\title{
DERECHO Y LITERATURA. ALGO DE LO QUE SÍ SE PUEDE HABLAR PERO EN VOZ BAJA
}

\author{
Enrique E. Marí \\ Universidad de Buenos Aires (Argentina)
}

«Si uno está interesado en las relaciones entre campos que a tenor de las divisiones académicas al uso pertenecen a departamentos diferentes, no se le acogerá como «constructor de puentes» como podría esperar sino que ambas partes tenderán a considerarlo un extraño y un intruso intelectual». Rudolf Carnap. Biografía Intelectual. Paidós. 1992

\section{I. ¿Construir un puente entre la literatura y el derecho?}

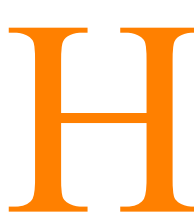
e aquí una pregunta que no deja de sorprender, en un doble sentido. En primer lugar, a causa de quien la formula. En términos muy genéricos, por cierto, pero no desprovistos de precisión. Puesto que si alguien, pongamos por ejemplo Gadamer, Dworkin, Posner, Fish, Nussbaum, Frisch o algún otro ocupante de los escenarios jurídicos o estéticos de nuestros días, se la hubiese planteado como posibilidad, Carnap se habría sentido perplejo con su daltonismo militante para cualquier tipo de ciencia no fácilmente traducible a la física. La construcción del puente de todos los puentes, eso sí que entraba, en cambio, en sus previsiones para agrupar, en particular, al conocimiento natural en la ciencia unificada de la metodología fisicalista. Pero literatura y derecho, sólo ofrecían ecos y resonancias poco simpáticas con los artículos de Erkenntnis y no más agradables al Journal of Unified Science o a la International Encyclopaedia of Unified Science.

Todos los enunciados descriptivos, incluso las predicciones, en cuya confirmación o rechazo Carnap veía la medida de la ciencia, eran para él reducibles a enunciados de observación, a proposiciones en los que se comprometen los individuos percipientes y los objetos que ejercen estímulos. Lo que había que evitar era «la ilusión de los sentidos» con respecto a estas coordenadas. Era la trabazón metafísica que se suele desprender de ellas, las aglomeraciones superfluas que obstruyen el lenguaje fenoménico. Los enunciados se comparan con enunciados y no con vivencias ni con el mundo, ni con ninguna otra cosa.

No es que el Círculo de Viena limitara el fisicalismo a las ciencias de la naturaleza; comprendía también las del espíritu, pero ¿en qué grado y sentido se podría atribuir a la estética, a la literatura o, más bien, a la crítica literaria, el carácter de una ciencia? La respuesta la va a dar con tono incisivo: en ninguno. 
«Aquí hay un cubo azul» es un enunciado que se encuentra, o está determinado por medio de coordenadas. ¿Se puede comparar el azul de este enunciado al «azul» del siguiente fragmento de Max Frisch en su novela No soy Stiller?: «Pero aquel día tampoco había mucha gente. Nuestro camino bordeado de juncos atravesaba un bosque de poco espesor. Los grupos de alisos, de abedules y de hayas, de vez en cuando un roble aislado, todos sin hojas todavía, nos dejaban ver grandes paños de cielo azul». En este caso los «grandes paños del cielo azul» no son aglomeraciones superfluas que obstruyen el lenguaje fenoménico. Por el contrario lo realzan, tomado éste en sentido no técnico. Se relacionan con las hojas grisáceas del otoño anterior, con la nueva hierba que las disimula, con la tierra empapada de humedad, con los pájaros que se reúnen en los cables de tensión para emprender su vuelo de migración al Norte. Sin estos «paños de cielo azul», así integrados, Rolf, acompañando a Stiller, no hubiera podido recordar aquel paseo como uno de los más hermosos de su vida, el lago Leman a la izquierda, el valle del Ródano a la derecha. Más que evitar la ilusión de los sentidos había que incentivarlos, había que coordinarlos en un amontonamiento conexo, había que percibirlos pero no, como proponía el Círculo de Viena, a la manera de meros estímulos cerebrales, como manchas en el sistema nervioso central, como procesos o fenómenos de la digestión, de la circulación de la sangre, o de inervaciones musculares.

Puesta la expresión los «paños de cielo azul» en algún artículo de un número de Erkenntnis, se consideraría, en cambio, un borrón que perturba la reverencia que se debe a la ciencia. Nuestro puente sería, en verdad, un puente semejante al del inolvidable film «El puente sobre el río Kwai», un puente construido para ser destruido de inmediato, en celada para el enemigo. Consecuencia, en nuestro caso, de otra guerra. La guerra de las ideas, las doctrinas y las teorías, aunque la destrucción no le ocasionaría tanto sinsabor a Carnap como al oficial inglés enamorado de su obra, representado por Alec Guinness.

Reiteremos los dos polos de la conexión presunta: el derecho y la literatura. Ni Carnap, ni el Círculo, se interesaron mucho por la ética y menos aún por el derecho. Sólo Schlick reconoció que de admitirse enunciados éticos en el marco científico los aceptaría en su condición de enunciados de hecho, que les atribuía. En cuanto a Carnap, afirmaba que no lo eran y tenían el estatuto de imperativos disfrazados. La literatura por su lado, como la poesía, está atravesada también en el interior del plano ficcional por enunciados potencialmente inverificables, potencialmente ajenos a todo test empírico. Y muchos de ellos son, a mayor abundamiento, incompatibles con la lógica y por ende incorrectos. Desacoplados de la sintaxis lógico-gramatical, alejados de la experiencia y de los procedimientos formales demos- 
trativos, inducen a engaño, son metafísicos, pseudoproposiciones. Tienen el mismo estatuto degradado de lo que hiciera Martín Heidegger en Was ist Metaphysik?, ${ }^{1}$ obra duramente juzgada por el autor de Introduction to Semantics quien la asimila a una máquina productora de pseudo-proposiciones, de Scheinsätze, juicio en que quizá haya influido -no sin justiciael recuerdo de las oscuras posiciones políticas del primero.

Carnap quiere ser preciso no sólo en cuanto a la metafísica y sus problemas esenciales -falta de significado empírico de las palabras y no concordancia de su secuencia con las reglas de la sintaxis- y acude para explicarlos a un cotejo entre ella y el arte. Si la metafísica posee un contenido éste no es teorético, no sirve para la descripción de relaciones objetivas, ni existentes, en cuyo caso sus proposiciones al menos serían verdaderas, ni inexistentes, caso en que serían falsas. Para lo que sirven sus enunciados no es ni más ni menos que para la expresión de una actitud emotiva ante la vida. Y qué otros enunciados pueden existir que expresen más adecuadamente esta actitud que la de los artistas, los hombres de letras, los poetas. Lo que ocurre es que éstos, afirma, saben que están en el terreno del arte y no en el de la teoría como les sucede a los metafísicos, que son músicos sin capacidad musical. Leamos su propia letra de «La superación de la metafísica mediante el análisis lógico del lenguaje»: «Pero el metafísico basa sus proposiciones en argumentos, exige con firmeza aquiescencia para lo que considera el contenido de las mismas, polemiza contra metafísicos de orientación distinta, tratando de refutar a través de su obra, lo que dicen. Por el contrario el poeta no trata de invalidar en su obra las proposiciones del poema de otro autor porque sabe que se halla en el terreno del arte y no en el de la teoría. Acaso la música resulte el medio de expresión más idóneo de esta actitud ante la vida, en vista de que se halla más fuertemente liberada de cualquier referencia a los objetos. El sentimiento armonioso de la vida, que el metafísico trata de expresar a través en un sistema monista, se halla mejor expresado en la música de Mozart. Y cuando el metafísico declara un sentimiento heroico ante la vida en un sistema dualista ¿no lo hará tal vez porque le falta la capacidad de Beethoven para expresar dicho sentimiento con un medio adecuado? En verdad los metafísicos son músicos sin capacidad musical, en sustitución de la cual tienen una marcada inclinación a trabajar en el campo teorético, a conectar conceptos y pensamientos» ${ }^{2}$.

El dictamen de Carnap es tajante. El hombre de arte, el novelista, tiene la ventaja sobre el metafísico de no confundir su papel, de descreer que és-

${ }^{1}$ Martín Heidegger. Was ist Metaphysik? Vittorio Klostermann, Frankfurt am Main, 1975.

${ }^{2}$ «La superación de la metafísica mediante el análisis lógico del lenguaje», Rudolf Carnap, incluido en El positivismo lógico, compilado por A. J. Ayer, F.C.E., México, 1965. 
te es teórico o cognoscitivo, de no estimar que está ligado al conocimiento. Sin embargo, esta ventaja subsiste pero es puesta inmediatamente en su lugar cuando se ocupa, precisamente, de la estética y del pensamiento normativo como la ética y el derecho. Dice en efecto: «El mismo dictamen puede aplicarse también a toda filosofía de normas o del valor así como a la ética o la estética como disciplinas normativas, ya que la validez objetiva de un valor o de una norma no es (y esto también de acuerdo con la concepción de los axiólogos) empíricamente verificable ni deductible de proposiciones empíricas y no puede, por lo tanto, ser afirmada de ninguna manera (y por medio de una proposición con sentido). En otras palabras, o se designan características empíricas para "bueno", "bello" y el resto de los predicados que se emplean en las ciencias normativas, o no. En el primer caso, una proposición que contuviera tales predicados se transformaría en un juicio fáctico y no en un juicio de valor En el segundo, devendría en una pseudoproposición. De cualquier modo, resulta imposible construir una proposición que exprese un juicio de valor».

Esta última proposición resuelve pues las cosas para el empirismo lógico á la Carnap con la mayor claridad, y gran carga de dogmatismo. Ni el derecho, ni la literatura (o cualquier otra expresión de la estética), tienen la más mínima posibilidad de convertirse en campos sobre los que se pueda construir algo racional, asociando racional con empírico y lógico-metodológico. Si vinculamos ahora a nuestro autor con Ludwig Wingenstein y su famoso punto 7 «De lo que no se puede hablar mejor es callar» («Wovon man nicht sprechen kann, darüber muss man schweigen») debemos concluir que el puente entre ambas disciplinas es algo de lo hay que callar, ante la imposibilidad de hablar de él. A Carnap, ni siquiera se le pasó por la mente hacer o discutir una propuesta de este tipo porque sabía que en los medios fisicalistas, y sobre todo atendiendo a sus lecciones, no iba a encontrar público, auditorio o interesado alguno. ${ }^{3}$

Sin embargo Carnap no tuvo en cuenta que, como a Monsieur Dupin en el cuento «La carta robada» de Edgar Allan Poe ${ }^{4}$, en décadas posteriores a sus trabajos, cuando el fisicalismo había perdido ya toda resonancia, a pen-

${ }^{3}$ Ludwig Wingenstein, Tractatus Logico-Philosophicus, Suhrkamp Verlag, Frankfurt am Main, Alemania, 1969, pg. 83.

${ }^{4}$ En otro trabajo, publicado en Papeles de Filosofía II, Buenos Aires, editorial Biblos, 1997, tuve ocasión de recordar el episodio en mi artículo «El retorno del caso Rivière». El pasaje de Poe es el siguiente: «...Si es un caso que requiere reflexión -Observó Dupin, absteniéndose de encender la mecha- lo examinamos en la oscuridad. -Esa es otra de sus extrañas ideas -dijo el Prefecto, quien tenía la costumbre de llamar "extrañas" a todas las cosas que superaban su comprensión y que vivía así entre una legión completa de "extrañezas"-. La idea del enlace derecho-literatura habrá de ser considerada «extraña» ante todo por los positivistas. Al superar su comprensión, viven, o afectan vivir, rodeados por una legión de extrañezas. 
sadores (no muchos) procedentes de la literatura, de la estética y de la filosofía del derecho, se les ocurrirían cosas «extrañas». Al punto de llevar a la superficie una propensión teorética transparente, exhibiéndose, así, como intrusos intelectuales. Para ello, tomaron los pentagramas de una música que repelía a Carnap, y se hicieron cargo del problema que los preocupaba y nos sigue preocupando: la construcción de un puente entre derecho y literatura. Es decir, la construcción de un puente entre estos dos campos que, si bien a tenor de las divisiones académicas al uso, pertenecen a disciplinas distintas, permitirían hablar de un enlace entre ellos, o de una influencia recíproca.

Ello exige a nuestro estudio hacer ingresar a los más destacados de estos pensadores, dar cuenta de las modalidades que propugnan para este enlace, de sus contradicciones y oposiciones, de sus dificultades y del régimen de análisis encarado por unos y otros, ya que no existe una línea común, sino más bien pensamiento cruzado, transversal y heterogéneo. Lo que los une, es que consideran que sí se puede hablar de este puente; lo que los separa, el régimen fonológico del habla. Hay quienes quieren hacerlo con fonógrafo; otros que prefieren susurros de enamorados. Hay quienes extienden y amplían los tópicos de la relación; otros que escogen temas parciales y ad hoc de acercamiento común.

Pero frente a las ideas del positivismo lógico, de Rudolf Carnap y del fisicalismo -que no consideran necesario mencionar-, saben que no hay ninguna posibilidad de hacerlo sin abandonar, sin dejar de lado las ideas que venimos de desarrollar de la corriente que imprimiera con tanta fuerza el marco de la epistemología en el primer cuarto de este siglo.

Ahora bien; antes de entrar en las reflexiones específicamente teóricas que nos brindan, vale la pena puntualizar el horizonte, el cuadro general en que hizo pie esta teoría. Aludo a la idiosincrasia personal del algunos poetas, literatos y letrados, cuando se refieren a cuestiones planteadas en el otro campo, pero aludo también a aspectos de la misma conexión que podríamos calificar de fáctica, de hecho cuya existencia reciproca se registra en las obras de derecho y de literatura, independientemente y antes de su aprehensión y alcance cognoscitivo.

\section{El enlace derecho y literatura antes de su captación en el marco de la teoría iusfilosófica y de la teoría estética}

A nuestro poeta, hablo de Mario Jorge de Lellis, no le gustaba el derecho. Para hablar con más precisión, quienes le disgustaban eran los abogados. En Cantos humanos (edición El Escarabajo de Oro, Buenos Aires), los percibía como los hombres de negro o, con más indulgencia, como los hombres de gris. No van a la feria como un abuelo dulce, no tienen el sol 
legañoso en los zapatos. No nos llegan heterodoxos, carpinteros, filósofos, albañiles. Carecen de la antigua zozobra del alquiler, de la herramienta húmeda, oxidada. Se parecen más bien a los hombres de la blanda cama, con sus sillones hondos y aburridos, con el centavo que suena en los bolsillos. Son, digamos, «los hombres del papel sellado», de ojos duros, talonarios y aromas de calas. No se les puede ofrecer un dorso de sus días, ni un quiosco entre las nubes. Siguen allí, con sus cuellos de oca, impenetrables, con acalabramiento largo entre los dedos y una vida impalpable de mínimos latidos.

Algunos siglos antes Johann W. Goethe, en su drama Goetz von Berlichinger, el Quijote suavo de la mano de hierro, que quería lograr la justicia, la igualdad y la libertad de los oprimidos fuera del «derecho establecido», expresaba acerca de ellos opiniones del mismo pulso, aunque diferente tenor argumentativo y contexto: el de los tribunales.

En la escena X del acto II se hace presente el derecho en la forma negativa de las acciones judiciales. En una boda de campesinos, Selbitz, del grupo de Goetz, enfrentado con los príncipes, el Obispo y Weislingen, considera un escándalo la rapiña de los asesores, y la sentencia confusa. Le pregunta al padre de la novia la duración del pleito con el ahora novio, recibiendo como respuesta: «Pues sus ocho años. Y antes querría que me tuviesen tostado al fuego otro tanto de tiempo que no volver a las andadas. No sabéis lo que hay que sudar para arrancarles por fin un fallo a estos tíos de las pelucas. Y después de todo, pescar una sentencia que reconocía a ambos el mismo derecho, con lo que siguieron como dos papanatas hasta que Dios le inspiró la feliz idea de cederle al contrincante su hija y las tierras objeto del litigio también. Sólo el asesor se le llevó sus buenos dieciocho florines de oro, y al novio otros quince. Lo que mueve a Selbitz a la siguiente reflexión: ¡Y nos llaman bandidos a nosotros!».

Pero, paradójico o no, lo cierto es que Goethe había seguido la vocación de su padre por el derecho, y recibido la influencia de Winckelmann, conectándose con la antigüedad clásica por la «vía romana». Estudiante de derecho romano en Leipzig y Strasburg, lo aplicó como ejercicio profesional en el Tribunal Cameral del Imperio de Wetzlar, y con Goetz von Berlichinger conforma la única pieza del teatro universal en la que se discute sobre el Código de Justiniano, el Corpus Juris y el derecho romano.

En la escena IV del acto I, Olearius, en el Palacio Episcopal de Bamberg, califica al Código de excelente, una compilación de todas las leyes. Para lo que pudiera parecer dudoso, ahí están, alega, las glosas con que los más doctos varones (recordemos a Bartolo de Sasoferrato, Cino de Pistoia y Baldo) realzan la obra que incluye, impliciter, los diez mandamientos. Precisamente la crítica que desliza al Consejo es que lo desempeñan suje- 
tos que están en ayunas respecto del derecho romano, se atienen a la tradición y a unos pocos estatutos y, para resolver los asuntos de leyes, creen que basta haberse formado, mediante los años y la experiencia, una idea exacta del estado interior y exterior de la ciudad. (Véase de Roberto Rey Ríos, Goethe y el Derecho Romano ${ }^{5}$, publicado por Abeledo Perrot y que constituye uno de los pocos trabajos en lengua castellana que da cuenta de este vínculo de Goethe con el Derecho Romano).

Es obvio que la conexión entre derecho y literatura está muy lejos de agotarse con la pieza comentada de Goethe. Alrededor de este mismo autor, cometeríamos la imperdonable omisión de no citar la obra que le abrió el Olimpo, el Fausto, no menos que la homónima de Christopher Marlowe, quien escribió las dos primeras tragedias del teatro inglés, si se toma en cuenta también Tamerlán el Grande. En estos textos (ambos Faustos) se dan noticia de la realización de contratos que hoy serían considerados nulos con ajuste a derecho ${ }^{6}$.

En la del dramaturgo inglés está también la vida, la tragedia y la muerte del sabio de Wittenberg, ebrio de ciencia y presunción, cuyas alas de cera volaron a zonas prohibidas, pero también está la ley, el contrato basado en la libertad del individuo, que aparece ya en la escena segunda del primer acto:

«Fausto:... ¡Adiós medicina! ¿Dónde está Justiniano?/Si se deja en herencia un mismo objeto a dos personas distintas, la una se quedará con él y se pagará a la otra el valor del mismo... Tal es el tema de las Instituciones/y de todo el cuerpo de la Ley!/Disciplina más propia de un ganapán a sueldo,/que a nada aspira sino a la hojarasca externa, demasiado mezquina y servil para mí. /Excluido lo demás, sólo resta la Teología/...».

Pero no es con ésta que Fausto espera satisfacer sus ilimitadas facultades, paralelas a las que Calígula, embriagado de poder, le expresaba a Cesonia en la obra del mismo nombre de Camus: apartar la luna de su órbita, cubrir los continentes con el océano, incurrir en la muerte eterna, responder a cuanto se le pregunte, asesinar a sus enemigos, asistir a sus amigos, vivir todos los placeres. No es con la teología, precisamente, sino con la magia y

\footnotetext{
${ }^{5}$ Esta obra fue publicada por Abeledo-Perrot, Buenos Aires, 1960. Según Rey Ríos, lo que nos manifiesta esta obra dramática con toda claridad es la lucha de Goethe por su personalidad, lucha que es ácrata, pues el individuo no reconoce leyes restringentes sino que quiere vivir bajo su propia ley. «Goetz tiene por su ideal que nadie necesite gobernar y nadie obedecer... El drama, aunque creado en forma caótica a los 22 años, contiene su credo político de revolucionario y ácrata "al que el viejo olímpico" de Weimar permaneció fiel hasta su muerte».

${ }^{6}$ Johann W. Goethe, Goetz von Berlichingen. El de la mano de hierro, Obras Completas, tomo IV, Aguilar, 1991, pg. 985. Fausto, pg. 773, op. cit. Christopher Marlowe, La trágica historia de la vida y la muerte del doctor Fausto, Edición Cátedra, Madrid, 1984.
} 
con la ayuda pactada de Lucifer asistido por Mefistófeles. Pues la Filosofía es odiosa y oscura, las Leyes propias de cerebros escasos y la Teología la más rastrera de las tres. Nada de lo cual se puede lograr sin la firma del pacto, que se preanuncia en el Acto II:

«Fausto:... Pues mira (se hace un corte en el brazo). Por amor a ti Fausto, se hace un corte/ en el brazo y con su propia sangre afirma/que su alma pertenece al gran Lucifer,/sumo Señor y Regente de la noche perpetua./Fíjate en esta sangre que gotea de mi brazo./iQue ella sea propicia a mis deseos!...»

«Mefistófeles: Pero redáctalo, Fausto/ con las fórmulas de una escritura de donación».

«Fausto: Sea. (Comienza a escribir)...»

Por supuesto, alrededor de estas obras, incorporadas al patrimonio de la cultura de occidente, como asimismo de El Mercader de Venecia de Shakespeare, con su relación contractual de la garantía de una libra de carne celebrada entre Antonio, en favor de Basanio, y Shylock, haciendo innecesaria la sagaz astucia de Portia, pero privando al mismo tiempo de todo efecto dramático a la obra, se ha producido en el campo crítico-literario un abundante material depositado en libros, artículos, monografías, tesis de doctorado, con pluralidad de interpretaciones sobre las condiciones contractuales que reflejan los textos.

Uno de los críticos a quien veremos luego enfrascarse en las polémicas cognoscitivas -aludo a Richard Posner-, luego de desarrollar el punto con amplitud, resume su opinión de esta forma: «Pero todo lo que deseo argumentar aquí es que Shakespeare celebra valores maduros como Homero, y en menor proporción Cozzens, pero no Camus en El Extranjero, y que estos valores implican una perspectiva del derecho en que el impulso primitivo de venganza y el más temprano estado formalista del derecho, son rechazados en favor de una más flexible o equitativa jurisprudencia, pero sin abrazar la ilusión de que la sociedad puede reemplazar el derecho con valores trascendentales. En cierta forma Shakespeare otorga a Shylock ciertas buenas líneas contra Antonio. No se debe olvidar la comparación de Antonio con un publicano servil (I.3.38). Hay algo que no es por entero saludable en Antonio -después de todo él firmó la garantía. Pensamos, creo, dar sentido a una afinidad entre él y Shylock, a despecho de los muchos puntos de oposición que los separan». ${ }^{7}$

No me parece aceptable esta opinión, que resulta en cambio muy coherente en el portavoz, más importante, con Gary S. Beeker, de la Escuela Eco-

${ }^{7}$ Richard A. Posner, Law and Literature. A Misunderstood Relation, Harvard University Press, Cambridge, 1988, pgs. 95-99. 
nómica del Derecho ${ }^{8}$, en razón del casi exclusivo sentido economicista que la distingue. Aquí no habré de discutirla a fondo, dado los límites de este trabajo, como tampoco discutiré, por los mismos motivos, El Rey Lear y Ricardo II. ${ }^{9}$ La opinión de Posner es, en cambio, suficiente prueba de una fracción de la enorme masa de material en que se entrecruzan literatura y derecho.

Llegados a este punto, una pregunta se hace visible: ¿acaso el enlace que se quiere ver entre derecho y literatura no será un simple expediente para mitigar esa mala impresión que poetas de la talla de los mencionados, y quizá en impensada revancha histórica contra Platón que los excluía de la ciencia, tenían del derecho y los juristas? ¿Un bálsamo quizá frente a ese negativo dictamen no sólo de estos poetas, sino también de una opinión pública muy generalizada? Creo, no obstante, que algo más ronda alrededor de esta propuesta y está relacionada con las cuestiones teóricas que venimos anunciando. De hecho la literatura se encuentra inundada de casos en que cuestiones legales cobran cuerpo. Existen ciertamente en las obras literarias múltiples y diversos temas relativos a la vida, la muerte, el crimen, la religión, la guerra, la familia y otras.

Dimos simplemente algunos ejemplos, muy aislados, de aquellos aportes que incorporan estas cuestiones jurídicas. Al que desee un testimonio más extendido de esta situación, le bastará recorrer los textos de Homero, Esquilo, Eurípides, Sófocles, Kleist, Dickens, Dostoievsky, Twain, Kafka, Camus, Melville, Zola, y los ya recordados Goethe, Marlowe y Shakespeare. Entre el derecho y la literatura, no menos que en el teatro, pues muchas de sus obras han sido llevadas a la escena, se tejen líneas elaboradas con hilo procedente de la otra bovina. En el cine y la televisión, a su turno, los juicios ante los Tribunales con jurados cuentan con especial inclinación del público, como lo explica Wilfrid R. Prest en The Rise of the Barristers. A Social History of the English Bar. «Los procesos legales, en efecto, tienen una dimensión escenográfica que justifica -observa Posner- que escritores de ficción como Sybille Bedford, Truman Capote, Rebecca West y Renata Adler, hayan dedicado sus talentos a describir los tribunales reales».

Muchos cuerpos de literatura se refieren a cuestiones de justicia, de la pena en juicios criminales, y la corriente utilitarista liderada por Jeremy

${ }^{8}$ Posner, junto con Becker, es uno de los más importantes representantes de la Escuela Económica de Chicago. En La Problemática del Castigo. El discurso de Jeremy Bentham y Michel Foucault, Buenos Aires, Hachette, 1983, desarrollo aspectos de esta Escuela. Como veremos más adelante, Martha Nussbaum, en su libro Justicia Poética, de la editorial Andrés Bello, Buenos Aires, 1997 , le formula una profunda y acertada crítica, que comparto.

${ }^{9}$ Aludo a Ricardo II, aunque superficialmente, en Papeles de Filosofía II, Biblos, Buenos Aires, 1997, en el art. «Las ficciones de legitimación en el derecho, y la política. De la sociedad medieval a la sociedad contractual». 
Bentham considera que son razones de utilidad que la convalidan, o sea, sus consecuencias valiosas para la prevención del delito o la disuasión (deterrence) de futuras acciones dolosas o culposas. El retribucionismo, por su lado, estima que la única razón que justifica la pena es la justicia lograda estricta y únicamente a través de la retribución (Kant). El reproche del utilitarismo al retribucionismo consiste en que, detrás de su argumento de justicia, lo que oculta es una simple cuestión de venganza.

He aquí un punto que ha llenado páginas y páginas de la literatura, a partir de las cuales el derecho está en condiciones de obtener conceptos apropiados. Páginas insertas, además de en las tragedias griegas, en El Cid, El Proceso, Rojo y Negro, los Pick-wick Papers, Una tragedia Americana, El Motín del Caine y otras piezas.

Entre los casos de venganza, existe uno, por demás paradigmático. Agamenón, repasemos La Iliada, había robado a Aquiles a su cautiva Briseida y desea restaurar heridas, calmarlo e incorporarlo a la lucha contra los troyanos. Pero ningún ofrecimiento apacigua su ira. Ni su devolución, ni la promesa de no haber subido nunca a su lecho, ni los diez talentos de oro, ni las veinte calderas, ni los siete trípodes aún no puestos al fuego, ni los doce corceles vencedores en los juegos, ni las siete mujeres lesbias primorosas en labores, ni otras futuras como hacerlo su yerno, honrarlo igual que a Orestes, su hijo menor, darle a elegir entre las tres hijas que habían quedado en el Palacio, llenar su nave hasta hartarse de riquezas si los dioses consentían destruir la hermosa ciudad de Príamo, darle siete populosas ciudades, unas junto al mar, otras abundantes en viñas y las veinte troyanas más hermosas, bastaron para calmar la cólera del hijo de Peleo. Para Ayax rechazar semejante oferta es «puro espíritu de venganza» de un misógino y anacoreta, que Aquiles visualiza, por su lado, como retribución, espíritu de justicia. ${ }^{10}$ ¿Cuál es el parámetro que separa el espíritu de venganza de la compensación, como ingredientes de la retribución? He aquí un problema a caballo de la literatura y el derecho implantado en las causas judiciales desde la más remota antigüedad.

Por otro lado, los jueces y los juristas ponen y deben depositar profunda atención en la selección de las palabras en que se expresan como en el uso de las metáforas y las similitudes que emplean en sus prácticas, y nadie pone en duda que una profunda versación literaria aplicada a sus respectivas labores los alejará de su condición de «hombres del papel sellado», permitiéndoles tomar la delantera en un momento en que la teoría de la argumentación y la retórica ocupan un lugar significativo en la teoría y la crítica jurídicas.

${ }^{10}$ Homero, Ilíada, Libro I, UNAM, 1996. 
Demos paso ahora a las cuestiones teóricas planteadas por filósofos, teóricos del derecho y críticos literarios, en el interior de esta problemática.

\section{La cuestión teórica del puente entre derecho y literatura}

Este puente ha sido considerado a través de una serie de puntos, siendo el central el problema de la interpretación de los textos jurídicos y los literarios. Hablar de interpretación y hablar de quien en la filosofía contemporánea es su más fiel cultor, Hans-Georg Gadamer, desarrollando sus ideas más básicas de Verdad y Método, es un requerimiento previo.

En el capítulo 10 de su obra nos indica: a) que la interpretación no es un acto complementario y posterior a la comprensión. Comprender es siempre interpretar, siendo la interpretación la forma explícita de la comprensión. b) que la aplicación es un momento integrante del proceso hermenéutico, tan esencial como la comprensión y la interpretación. Comprender es aplicar. En el caso de un texto jurídico, su conocimiento y aplicación a un caso concreto no son dos actos separados, sino un proceso unitario. La interpretación plantea una tensión entre los interlocutores en un vínculo diádico; o entre el lector y el texto a interpretar por un lado y, por el otro, la situación cambiante en que se trata de entenderlo. Buena parte de esta tensión se juega en la relación temporal pasado-presente. El sentido de la ley en su aplicación normativa no es, en principio, algo distinto del sentido de algún otro tema, tal como se hace valer en la comprensión de un texto.

Este segundo segmento le da la puerta de entrada para su tercer principio esencial: e) la unidad frente a la diversidad de los textos. «El caso de la hermenéutica jurídica no es por lo tanto un caso especial, sino que está capacitado para devolver a la hermenéutica histórica todo el alcance de sus problemas y reproducir así la vieja unidad del problema hermenéutico en la que vienen a encontrarse el jurista, el teólogo y el filólogo».

Ahora bien, la unidad de la hermenéutica excede estas tres dimensiones. La literatura, y la estética en general, no dejan de estar presentes en el marco hermenéutico gadameriano. La literatura no sólo aparece en el capítulo 10, que seguimos, en relación a lo jurídico, sino que es objeto de una serie de artículos recopilados en Estética y Hermenéutica. ${ }^{11}$ Para Gadamer el concepto de interpretación llega a su plenitud allí donde el sentido de un texto, cualquiera que fuese la disciplina a la que perteneciere, no se comprende in-

${ }^{11}$ Verdad y Método fue publicado por la colección Sígueme de Salamanca en 1977 y Estética y Hermenéutica por Tecnos, Madrid, 1996, compilación de una serie de artículos, con el siguiente acápite de su autoría que lo enfrenta a Habermas, por su crítica a la Modernidad: «En este momento de nuestra historia, el significado filosófico del arte reside principalmente en el modo de pensar de la filosofía. Así, cada recuerdo del arte es un correctivo a ese carácter unilateral de la orientación moderna del mundo». 
mediatamente, allí donde no se quiere confiar en lo que un fenómeno, sobre todo llevado a escritura, representa inmediatamente. Para el historiador, por ejemplo, es un supuesto fundamental que «la tradición» debe ser interpretada en un sentido distinto del que los textos, y añadamos la intención de sus autores, pretenden por sí mismos. ${ }^{12}$

En una primera mirada la literatura parece llegar a su extremo de liberación respecto de toda ocasión y contingencia que aún afectaba a la declaración pública (o a la puesta en escena). De cualquier libro, y no específicamente de éste sólo, puede decirse que es para todos y para ninguno. ¿Pero es éste, se pregunta nuestro autor, el concepto correcto de la literatura? ¿El espacio-imago que genera, es un espacio de fanciful imagination, descomprimido de toda captación comprensiva? La existencia de la literatura no es la permanencia muerta de un ser enajenado que estuviera entregado a la realidad vivencial de una época posterior, en simultaneidad con ella. La relación presente/pasado, y su modo de desentrañarla por la hermenéutica, está tanto presente en la literatura como en la materia jurídica (la filología, la filosofía, etc.).

Ahora bien, ¿cuál es el modo de desenraizar esa relación presente/pasado? En Estética y Hermenéutica Gadamer expresa su punto de vista, aludiendo al arte en general: «la realidad de la obra de arte y su fuerza declarativa no se dejan limitar por el horizonte histórico originario en el cual el creador de la obra y el contemplador eran efectivamente simultáneos. Antes bien, parece que forma parte de la experiencia artística el que la obra de arte siempre tenga su propio presente, que sólo hasta cierto punto mantenga en sí su origen histórico y, especialmente, que sea expresión de una verdad que en modo alguno coincide con lo que el autor espiritual de la obra propiamente se había figurado».

A esto le podemos llamar indistintamente imaginación creadora del genio o, desde la mirada del contemplador, inagotabilidad conceptual de toda declaración artística. La literatura es una función de la conservación y de la transmisión espiritual que, a cada presente, aporta la historia que se oculta en ella. Pero hay que entender bien esta función ya que no se limita a conservar lo que hay, sino que lo reconoce como patrón y lo transmite como modelo. Está siempre referida al receptor. ${ }^{13}$

${ }^{12}$ La crítica de Jürgen Habermas al concepto de tradición e historia en Gadamer, frente al cual propone el de «reflexión», consta en mi artículo «La interpretación de la ley» agregado a Materiales para una teoría crítica del derecho, AAVV, Editorial Abeledo-Perrot, 1991.

${ }^{13}$ En tierras germánicas se desarrolla en este siglo una de las más importantes corrientes que remite al receptor, o sea al lector del libro en literatura, o a los jueces en el medio jurídico, los derechos sustanciales de la interpretación. Se la conoce como Estética de la Recepción y son sus cultores más destacados Hans Rober Jauss, Wolfgang Iser, Bernard Zimmerman des- 
Nada distinto ocurre con el derecho y su interpretación, en donde también aparece un lector con un texto ante sus ojos. Tampoco aquí este lector leerá simplemente lo que el texto pone en el pasado para él, conforme a su sentido originario. En toda lectura jurídica tiene lugar una aplicación y el que lee un texto se encuentra también él dentro del mismo, conforme al sentido que percibe a novo.

No obstante, ocurre con el jurista que entiende el texto en continuidad y con la transmisión histórica del sentido original en el presente. Si intenta realizar la pervivencia del derecho, lo hace como un continuum para salvar, a la manera dogmática, la idea jurídica. ¿Qué otra cosa sino esta tarea, que excluye la auténtica hermenéutica, se propusieron Savigny y Schleiermacher, confundiendo sentido jurídico con sentido histórico de la ley? El primero, entendiendo en System des römischen Rechts la tarea de la hermenéutica jurídica como puramente histórica. El segundo, no viendo problema alguno en que el intérprete se equipare con el lector originario, ignorando, ambos, por ende, la tensión entre sentido jurídico originario y actual. Mientras que Ernst Forsthoff puso las cosas en su adecuado sitio, mostrando que por razones jurídicas es necesario reflexionar sobre el cambio histórico, ya que sólo éste permite distinguir entre el sentido original del contenido de una ley y el que se aplica en la praxis jurídica.

Ello, prestemos atención, no quiere decir que el jurista no se refiera siempre a la ley en sí misma. Lo que quiere decir es que su contenido normativo tiene que determinarse respecto al caso en que acaece la aplicación. Y aunque no cabe prescindir de un conocimiento histórico del «sentido originario», no le es dado, ni está obligado a sujetarse a lo que los protocolos parlamentarios le enseñarían respecto a la intención de los que elaboraron la ley. Por el contrario, tiene que admitir que las circunstancias han ido cambiando y que la función normativa de la ley debe ir determinándose de nuevo.

Los focos centrales de Gadamer que hemos explicitado, a saber, comprender es siempre interpretar; comprender es aplicar; y la unidad de la hermenéutica, se convierten en un marco general que orienta, en mayor o menor grado, a los teóricos del derecho y a los de la estética, que aceptan el habla sobre el puente derecho/literatura. Veamos algunas de sus observaciones, comenzando con las procedentes del derecho, las de Richard A. Posner y Ronald Dworkin, advirtiendo que el marco de las ideas de Gadamer no es aceptado in totum, sirviendo, más bien como guía global, como pará-

de el campo marxista, Hans Ulrich Gumbrecht, y Odo Marquard. Publican en Wilhelm Fink Verlag la importante colección Poetik und Hermeneutik, cuyo tomo X está destinado a Funktionen der Fiktiven. Esta escuela habrá de jugar un relevante papel en el tema interpretativo, enfrentando la tesis opuesta de la interpretación concedida como derecho exclusivo «al autor». Desempeña un papel antifundacionalista, sustentado en el autor. 
metros sin los cuales no sería factible ni siquiera intentar la arquitectura del puente en estudio.

En Law and Literature. A Misunderstood Relation, el exhaustivo y precioso libro -ante citado- sobre el tema, aunque pleno de eclecticismo, Richard A. Posner ${ }^{14}$ «parte de un poema de Wordsworth, para afirmar que el poeta, igual que el legislador, conoce que los cambios distantes en una cultura y sociedad no pueden ser previstos. Quizá las intenciones de Wordsworth fueron crear una obra de literatura y sabemos que, para que una obra de literatura sobreviva debe, en forma semejante a una provisión legal o constitucional, ser hospitalaria con el cambio social y cultural. Si se insiste en que el único significado de una obra arte es uno consistente con la comprensión del artista que la creó, no se logra ir más allá de una estricta actividad pedagógica. En verdad, constituye una proeza académica -que no requiere más que una vida de estudio disciplinado y, quizá, inalcanzable-, penetrar en la mente de la antigua Grecia o del renacimiento inglés, al margen de toda la devoción y esfuerzo que se ponga en la tarea.

Pero no se necesita ser un epígono de Gadamer -afirma Posner- para concordar en que, leyendo literatura de otra cultura, no es factible renunciar a su propia identidad cultural. La comprensión (Verstehen), como la traducción, es mediación y no reconstrucción. Lo que no implica un handicap completo, pues los contemporáneos del autor no siempre se encuentran en condiciones de comprender una obra de arte como lo hacen miembros inteligentes de otra cultura posterior. El siguiente párrafo concreta este hilo de razonamiento: «El conocimiento de la historia de los irlandeses, los judíos, y los negros, podría muy bien ayudar a entender aspectos de Easter 1916, ${ }^{15}$ el poema de Yeats, El Proceso y Otelo, que sus autores y audiencias originales no habrían entendido».

No sólo por esta coincidencia interpretativa, Posner piensa que con Gadamer culmina la escuela germánica de la hermenéutica, sino que Nietzsche es el más importante andamiaje a la interpretación-del-lector, en la crítica literaria.

En efecto; si «el mejor significado» fuese el que sólo la historia literaria estuviese habilitada para recubrir a través de proezas heroicas de la investigación y la imaginación, ¿cómo podríamos estar seguros sobre cuál es el significado que el autor se propuso? ¿Habrían deseado Homero y Shakespeare la preservación y conservación de sus obras únicamente por los scho-

${ }^{14}$ El libro alude a Gadamer en las pgs. 236 y 239.

${ }^{15}$ Se refiere al poema de Yeats, cuyo título y referencias oblicuas revelan su sentido acerca de la rebelión irlandesa de Easter durante la primera guerra mundial, reprimida con fiereza por las tropas británicas. 
lars? El concepto de intención del autor en literatura, sostenido por Hirsch, Juhl y otros intencionalistas, se hace de más en más evanescente.

Pero dejemos este problema de la intencionalidad para un trato posterior, pues lo que de momento nos concierne es cómo el marco general de ideas de Gadamer brinda sólido apoyo a los juristas y hombres de letras que simpatizan con el tendido del puente entre ambas disciplinas.

No obstante, antes de cerrar esta cuestión de la intencionalidad, brindemos un corto espacio a uno de los puntos que le sirven a Posner para marcar una distinción, que considera indiscutible, entre lo literario y lo jurídico.

En efecto, dice, un poeta trata de crear una obra de arte, por ejemplo Wordsworth con «A slumber did my spirit seal», o sea, algo estético, hermoso y placentero. Si tiene éxito, no nos preocupamos de cuán banales fueron sus intenciones, si fracasa tampoco nos preocupa lo elevadas que fueron. La legislatura, sin embargo, está dando mandatos a sus subordinados en nuestro sistema de gobierno, es decir, a los jueces que deben aplicar la legislación en casos específicos.

Un mensaje cualquiera, se propone, por cierto, instalar una cadena directa entre la mente del que lo emite y la de quien lo recibe. La orden, por el contrario, no opera a la manera de un mensaje para ser decodificado, en un sistema de comunicación, de acuerdo con las intenciones del remitente. Si un mensaje llega ser falseado en la transmisión, pides que el remitente lo repita. Si no puedes alcanzarlo, tratas de indagar, a partir de todo lo que conoces de él y de las circunstancias del fracasado mensaje, qué pudo haber significado, ya que un correcto análisis es intencionalista. Una de las cosas que da al intencionalismo su fuerza en la crítica literaria es la fascinación romántica con la personalidad del artista, o sea, la concepción romántica de la obra de arte como una emanación más que artefacto. Pero, en cambio, una ley, un estatuto, es una emanación, una condición de su autoridad.

De todos modos, Posner no habrá de limitar, insistamos en ello, su distinción entre lo jurídico y lo literario a este aspecto. Pero antes de considerar los otros puntos importantes de su disidencia, pasemos, ahora, a examinar cómo el pensamiento de Dworkin, el otro jurista, está ligado al marco de Gadamer.

Las obras en que Ronald Dworkin se ocupa de derecho y literatura son A matter of Principle, Law's Empire y Taking Rights Seriously ${ }^{16}$, y específicamente de Gadamer en el segundo. En un segmento de este texto, «El ar-

${ }^{16}$ El primero fue editado en 1985 por Harvard University Press, London. Los segundos cuentan con traducción castellana: El Imperio de la Justicia, editorial Gedisa, 1992, y Los derechos en serio, editorial Planeta Argentina, 1993. Mis citas responden a estas ediciones en español, salvo en el caso del primer libro. 
te y la naturaleza de la intención», Dworkin se pregunta si la interpretación artística es inevitablemente el descubrimiento de las intenciones del autor (Frisch, Juhl), y si este descubrimiento constituye un proceso objetivo independiente de los propios valores del intérprete. La interpretación, responde, no es sólo el hecho de recuperar la intención de un autor si entendemos que intención significa un estado mental consciente. El objetivo de la interpretación artística, asunto complejo y problemático, no es siempre identificar una idea consciente en la mente del autor cuando dijo, escribió o hizo lo que hizo. La cruda concepción del «estado mental consciente» no es un paraguas, un umbrella que proteja todo el tema de la interpretación. Por eso cuando Gadamer habla de la intención su expresión admite cualificaciones en Dworkin, que lo conducen más que a descubrir la intención del autor (teoría que Dworkin rechaza), a encontrar un valor en lo que ha hecho.

El teatro proporciona una buena muestra. Su remisión es al poli-mencionado ejemplo de El Mercader de Venecia, que hoy en día (recordemos que efectivamente así lo hizo Posner) debe encontrar en una audiencia contemporánea el complejo sentido que en Shakespeare y su público tenía la figura de un judío, de modo que su interpretación debe unificar dos períodos de «consciencia» adaptando una cultura muy diferente a una historia distinta. Si logra hacerlo, su interpretación de Shakespeare será muy distinta de la que para él tenía ese personaje. La fidelidad presente a las opiniones más concretas del autor puede convertirse en una traición a sus propósitos artísticos más abstractos. Y la aplicación de ese propósito abstracto no constituye un ejercicio histórico y neutral sobre la reconstrucción de un estado mental del pasado.

Para Dworkin existe una complicada relación entre la intención y el valor del arte. Las obras de arte se presentan poseyendo un valor del tipo que denominamos estético. Esta forma de presentación forma parte de la idea de la tradición artística; y le permite avanzar una de sus posiciones en materia de interpretación constructiva, que apunta a hacer de ella la mejor lectura de aquello que se interpreta (aunque a veces se busca, se intenta «hacer aparecer» tal situación). ${ }^{17}$ Pero Dworkin trata de ser cuidadoso y no desea que se

${ }^{17}$ En su lectura de Law's Empire de Dworkin, Françoise Michaut sostiene que suponer que hay que dar a las prácticas jurídicas la mejor lectura posible y no verlas como son, invita al juez a escoger lo que va a mejorar la calidad del producto. Equivale a pensar que el derecho es naturalmente bueno y que sólo la maldad del hombre puede pervertirlo, lo que ha movido a considerar a Dworkin un iusnaturalista. El «criterio de la conveniencia», o de «a convenance», propio de la coherencia narrativa, implica que el juez debe decidir el caso con la ayuda de una regla que resulte de la mejor interpretación de la historia jurídica pasada. Este criterio ha envuelto a Dworkin en una polémica abierta con Neil MacCormick y A. Aarnio, que Jacques Lenoble, apoyando al primero, desarrolla en «La théorie de la cohérence narrative en droit», Archives de Philosophie du droit, Sirey, París, tomo 33. 
lo malinterprete: «No estoy diciendo que la teoría de la intención del autor de la interpretación está equivocada (o es correcta) sino que si es correcta o incorrecta y lo que significa (mientras podamos pensar sobre estas cuestiones dentro de nuestra propia tradición de crítica) debe abrir la posibilidad más fundamental de indagar por qué las obras de arte tienen el valor que presupone su presentación... La situación interpretativa no es un principio de Arquímedes, tampoco es lo sugerido por la idea de que el objeto de la interpretación es hacer parecer de la mejor manera posible aquello que se interpreta. Una vez más apelo a Gadamer, cuya descripción de la interpretación, a pesar de luchar en contra las restricciones de la historia, da en la nota exacta».

Ahora bien, en el ámbito de los críticos literarios, a su turno, Gadamer sigue siendo referente obligado, al margen de que las opiniones difieran entre ellos y, a su vez, con los teóricos del derecho.

Comencemos por el análisis de Stanley Eugene Fish en Doing What Comes Naturally, un volumen que, conforme a su subtítulo, es dedicado al cambio, la retórica y la práctica de la teoría en la literatura y los estudios legales. ${ }^{18}$ Este texto ubica al filósofo alemán en el grupo de los antifundacionalistas. El antifundacionalismo nos enseña que las cuestiones de hecho, verdad, corrección, validez, y claridad, no pueden ser planteadas, ni contestadas, en referencia a algo extracontextual, ahistórico, realidad no-situacional, regla o derecho o valor. Todas esas cuestiones son inteligibles o discutibles sólo en el interior de precintos de los contextos o situaciones, o paradigmas o comunidades, que les dan su forma local y cambiable. El antifundacionalista no reemplaza los componentes de la pintura del mundo fundacionalista con otros componentes. Lo que hace es denegar a estos componentes la estabilidad, independencia, e incluso la identidad que les es necesaria si ellos deben ser pensados como fundamentos o anclas. Entidades como mundo, lenguaje, Yo, pueden todavía ser nombradas y los juicios de valor que tienen que ver con la validez, facticidad, precisión y propiedad, junto con los procedimientos por los cuales pueden ser identificados, serán inextricables, inseparables, de las circunstancias sociales e históricas en el interior de las cuales deben obrar. La concepción fundacionalista ya no se sostiene: todo lo que hay en este tipo de discurso se ha convertido en dependiente irreductiblemente de lo histórico, lo contingente, lo variable y lo

18 Texto editado en 1989 por la Duke University Press. Extraigo la observación sobre Gadamer, y los otros antifundacionalistas, de la página 345. Véase, asimismo, Is There a Text in this Class?, Harvard University Press, Cambridge, 1980. Sobre la problemática literaria Narratology. Introduction to the Theory of Narrative, de Mieke Bal, University of Toronto Press, 1885, y sobre narración y derecho, Constitutional Law as Fiction. Narrative in the Rhetoric of Authority de L. H. La Rue, Pennsylvania State University Press, 1995. 
teórico. El fundamentalismo yace en ruinas, pues lo que afirma que lo trasciende, en realidad, lo implica.

Los argumentos antifundacionalistas se extienden a varias disciplinas, en sus más diversas vías. Fish coloca a Gadamer en este grupo, junto a Richard Rorty, Hilary Putnam, W.V. Quine en filosofía; Clifford Geertz y Victor Turner en antropología; en historia Hayden White; en sociología la escuela de la sociología del conocimiento; en forma más reciente los endometodólogos; en hermenéutica Heidegger, nuestro autor y Derrida-, en ciencias del hombre Michel Foucault; en historia de la ciencia Thomas Kuhn; en historia del arte Michael Fried; en teoría jurídica Philip Bobitt y Sanford Levinson; en historia literaria Barbara H. Smith, Walter Michaels, Jonathan Culler, Terry Eagleton ${ }^{19}$, Stanley Fish. La lista es interminable y Fish da un cuadro apropiado de cómo se encadenan las discusiones, resaltando, en particular, la cercanía de Gadamer con el deconstrucionismo de Derrida y Culler. Por supuesto el fundacionalismo ha contraatacado con ideas que no han dejado de convertirse en un estribillo, en una muletilla: lo que ofrece el antifundacionalismo es inconsistente, sus riesgos son la pérdida de la investigación racional y la comunicación exitosa.

Desde luego entre los fundacionalistas más extremos habrá que colocar a los positivistas herederos del fisicalismo. Al referirse a esta cuestión Israel Scheffler observa con acuidad que al sostener una racionalidad independiente de los contextos sociales y culturales, y sin el ancla de determinados hechos, el fundacionalismo pierde los controles, hace estéril la comunicación y convierte en una alucinación el universo común de las cosas. «...En lugar de una comunidad de hombres racionales en persecución de la verdad, tenemos un conjunto de mónadas aisladas en cuyo interior se forma la creencia sin constricciones sistemáticas»..» ${ }^{20}$

Entre los críticos de literatura, uno de los más próximos al fundacionalismo, aunque rechaza el positivismo, es en cambio E.D. Hirsch, Jr., con su libro Validity in Interpretation, ${ }^{21}$ quien dedica el Apéndice II, completo, para refutar la teoría de la interpretación de Gadamer, y combatir la tesis de lo que llama el destierro del autor, «the banishment of the author».

Hirsch reconoce que el trabajo de Gadamer es el aporte más sustancial escrito en Alemania en este siglo, contra la preocupación del siglo XIX por la verdad objetiva y el método correcto planteada por la obra de Boeckh con

${ }^{19}$ De Robert A. Ferguson, jurista, es digno de verse su texto Law and Letters in American Culture, Harvard University Press, Cambridge, 1984, donde analiza, entre otros, textos de Jefferson y Lincoln.

${ }^{20}$ Israel Scheffler, Science and Subjectivity, Bobbs-Merrill, 1917, pg. 19.

${ }^{21}$ Publicado por la Universidad de Yale, en 1967. 
su título sintomático Encyclopädie und Methodologie der philologischen Wissenschaften. Gadamer protesta contra la posibilidad de que exista una metodología de la interpretación textual ya que, al fin y al cabo, la interpretación no es una ciencia cuya meta sea el conocimiento objetivo y permanente. La verdad no puede residir, como piensa Hirsch junto a Boeckh, en la genuina recognición del significado del autor.

Para Gadamer semejante opinión se basa en un ideal ingenuo irrealizable, pues cada lectura del texto es una nueva y diferente cognición. En realidad, lo que el siglo XIX pasó por alto es la historicidad de la comprensión, y ya conocemos la firme idea de Gadamer: ningún método puede trascender la propia historicidad del intérprete, ninguna verdad puede trascender esta verdad central, ninguna interpretación relevante puede estar gravada por la intención original del autor.

Hirsch, obrando como fundacionalista, rechaza todos estos criterios que no tienden sino a desterrar al autor original. En la siguiente frase podríamos encontrar una buena síntesis de su pensamiento: "Así, cuando los críticos deliberadamente destierran al autor original, ellos mismos usurpan su lugar, y esto conduce infaliblemente a algunas de las confusiones teóricas de nuestro presente. Donde antes no debía existir más que un autor, ahora emerge una multiplicidad de ellos, cada uno acarreando tanta autoridad como el siguiente. Desterrar al autor original como determinador del significado era rechazar el único principio normativo, compulsivo, que podía asignar validez a una interpretación». Como se ve, Hirsch está hablando de literatura, pero no es casual que aparezcan en este segmento palabras como «normativo», «compulsivo», «validez», propias del vocabulario jurídico, ya que la interpretación actúa como problema-enlace entre derecho y literatura. ${ }^{22}$

Este tópico, el examen del sentido en que el pensamiento de Gadamer funciona como referente común de los filósofos del derecho y los críticos de la literatura, el grado en que funciona como un foco de atracción -lo que no excluye las críticas-, nos ha permitido, al mismo tiempo, ir desarrollando algunas de las ideas que se centran en nuestro tema, el del puente de las dos disciplinas, puente «extraño» en el uso que Monsieur Dupin daba a esta palabra y más que puente, quizá, una simple pasarela. Para ver si se trata, en todo caso, de una pasarela sujeta a oscilación, con riesgo de bambolearse a la más leve brizna teórica, de un puente sobre el río Kwai o de una estructura sólida, cabe ahora recuperar a nuestros autores en su estudio directo de esta problemática.

${ }^{22}$ Op. cit. pg. 5. 


\section{Comencemos por Ronald D. Dworkin}

En las tres obras que citamos anteriormente, Dworkin se ocupa del problema de la interpretación en el derecho y en la literatura. Su posición es evitar dos puntos de vista que considera extremos e inapropiados: a) que al decidir un caso legal los jueces encuentran el pleno significado del derecho «just there»; b) que lo construyen por entero, conforme a sus preferencias personales o antojo.

Encontrar y construir son dos verbos que interpelan a dos situaciones muy disímiles. Encontrar, «find», lleva al intérprete a suponer que está exonerado de todo trabajo interpretativo, pues éste se agota en abrir los ojos al texto que está allí o que el legislador habría preparado, dándole por servida al juez la comprensión/aplicación del mismo (que en Gadamer eran la misma cosa).

Construir, hacer, realizar, make up, equivale a inventar de acuerdo con su preferencia, predilección, propensión o, incluso, cariño. Dworkin liga este argumento sobre la práctica legal con el mismo argumento de la práctica de la crítica literaria. No se olvida que en ambas disciplinas la cuestión básica es identificar la fuente de la autoridad interpretativa y que, en las dos, la respuesta que se da toma la forma típica de dos posiciones que rechaza.

Así como en la comunidad legal representantes de la primera opinión insisten en construir las decisiones estrictamente, o sea, atendiendo a las palabras mismas de la ley, ${ }^{23}$ también los hay en la comunidad literaria que han insistido en que interpretación es, o debiera ser formulada, por lo que está en el texto (Hirsch). En forma análoga, en el derecho y la literatura está presente la posición opuesta: el realismo sostiene que las lecturas de los jueces son siempre racionalizaciones de sus deseos personales o su política, en tanto partidarios de la subjetividad crítica sostienen que lo que el lector ve es un mero reflejo de sus predisposiciones y prejuicios. El campo, como se advierte, está seccionado entre aquellos que creen que la interpretación está fundada en la objetividad y aquellos que piensan que los intérpretes son libres, para todos los intentos y propósitos.

A fin de flanquear ambas posiciones, Dworkin formula su propia posición, conocida como «la empresa en cadena», en la que se concibe a la interpretación como la extensión de una historia institucional hecha de innumerables decisiones, estructuras, convenciones, y prácticas. Así concebida no es puramente objetiva puesto que deja espacio para el desacuerdo, pero

${ }^{23}$ Recordemos la posición de Sebastián Soler (Las palabras de la ley, F.C.E., México, 1969) en la controversia con Genaro Carrió, de la que éste da cuenta con su sabia respuesta en Algunas palabras sobre las palabras de la ley, Buenos Aires, editorial Abeledo-Perrot, 1971. 
tampoco es completamente subjetiva ya que el intérprete no debe proceder independientemente de lo que, en la institución, otros han hecho o dicho.

El ejemplo literario que ofrece Dworkin es una novela no escrita por un sólo autor, sino por un grupo de ellos, siendo cada uno responsable de la redacción de un capítulo separado. Los miembros dejan que la suerte determine quién habrá de redactar el primero (y los siguientes), y una vez hecho esto, el redactor del capítulo lo remite al próximo número, con el entendimiento que él, o ella, está agregando un capítulo a la novela más que comenzando una nueva y luego envía los capítulos al próximo número y así sucesivamente, hasta su terminación. Ahora bien, cada novelista, excepto el primero, tiene la doble responsabilidad de interpretar y crear, puesto que cada uno debe leer lo que se ha hecho a fin de establecer, en el sentido interpretativo, en qué consiste la novela así creada. Debe decidir qué son «realmente» los personajes, qué motivos de hecho los guía, cuál es el punto central o el tema de la novela que se está desarrollando, hasta qué punto algún recurso literario o figura, usado consciente o inconscientemente, contribuye a esto, y si debería ser extendido o refinado, orientado o abandonado, a fin de que la novela tome una dirección u otra.

Esta teoría ha recibido numerosas críticas, ante todo procedentes del campo de los fundacionalistas. Pero antes de abordarlas, integremos un poco más el panorama con sus ideas sobre la «chain enterprise», el puente entre derecho y literatura.

En el capítulo 6 de $A$ Matter of Principle, a saber, «How Law is Like Literature?», retoma el tema con amplitud, lo que nos induce, aunque brevemente, a analizar algunos de sus principios y aspectos.

a)Si la interpretación tiene que formar la base de una teoría más plausible sobre las proposiciones del derecho, habrá que añadir un informe más inclusivo de lo que es. Lo que esto quiere decir es que los juristas no deben tratarla como una actividad sui generis. La debemos estudiar como una actividad general (el principio de la unidad de Gadamer), como un modo de conocimiento (el principio de Gadamer de que comprensión e interpretación es la misma cosa), atendiendo a otros contextos de esta actividad. Los juristas harían muy bien en estudiar literatura y otras formas de la interpretación artística. (Un consejo que Carrió, pese a su brillo y estar enfrascado en la temática, influido más por las cuestiones lingüísticas, no supo o no deseó escuchar) ${ }^{24}$. Dadas las controversias que separan a los hombres de de-

${ }^{24}$ Carrió, en el momento de la polémica con Soler, conocía profundamente a Dworkin. Véase de él «Dworkin y el positivismo jurídico», Cuadernos de Crítica, UNAM, n. 16. Por ello, conjeturo que no le interesó el enlace law-literature, al margen de su pertenencia al antifundacionalismo. 
recho en materia de interpretación, esto parecería ser un mal consejo, pero son precisamente esas divergencias las que resultan de sumo interés para ellos. En la literatura se han defendido muchas más teorías que en el derecho y, en ello, se incluyen doctrinas que han cuestionado la alicaída discusión entre descripción y evaluación, que ha debilitado a la teoría jurídica.

b) Su interés no recae en saber cómo un autor usó una frase o una palabra, sino en el significado de una obra, como un todo. Sugiere, aquí, la aparentemente banal «hipótesis estética», que plantea así: la interpretación de una pieza de literatura intenta mostrar qué modo de lectura (o de expresión, dirección o actuación) revela al texto como la mejor obra de arte. Diferentes escuelas o teorías o tradiciones no habrán de estar conformes con ella, porque asumen diferentes teorías interpretativas acerca de qué es el arte, o para qué sirve, y qué hace a una obra de literatura mejor que otra. Pero la hipótesis estética no es tan débil ni relativista como puede parecer a primera vista.

c) Las teorías del arte no existen aisladas de la filosofía, la psicología, la sociología y la cosmología.

d) La hipótesis estética tiene la consecuencia de que las teorías académicas de la interpretación no habrán de ser vistas como ellas a menudo reclaman, a saber, análisis de la verdadera idea de la interpretación, sino más bien como candidatas para la mejor respuesta a las cuestiones sustanciales planteadas por la interpretación.

e) Dworkin despliega una amplia gama de argumentos contra el intencionalismo. Los intencionalistas, como Hirsch entre otros, hacen del estado mental del autor el centro de la interpretación. Pero no consideran ciertas complejidades en tal estado mental. Fracasan en apreciar cómo interactúan las intenciones «para» una obra y las creencias «acerca» de ella.

f) Existen misterios irresueltos en el intencionalismo, frente a los cambios en la intención del autor. El creador repentinamente ve algo «en» la obra que antes no había advertido. Por ejemplo, John Fowles en medio de la composición de La mujer del teniente francés. ¿Pudo, quizá, también haber cambiado cuando vio el film o la interpretación de Merryl Streep? Los intencionalistas eligen dos alternativas para estos casos. El autor piensa súbitamente que ha tenido una «intención subconsciente» previa, o bien que ha cambiado su intención más tarde. En este caso no puede atribuir el cambio al descubrimiento de su previa intención. El cambio no se ha producido confrontando su anterior Yo, sino simplemente la obra que él ha creado. La escuela intencionalista convierte el valor de una obra de arte en un estrecho y coactivo punto de vista de las intenciones del autor.

g) La interpretación literaria se propone mostrar de qué manera la obra puede ser vista como la más valiosa, de modo que debe atender a rasgos for- 
males de identidad, coherencia e integridad, tanto como a cuestiones sustantivas de valor artístico. Ahora bien, una interpretación plausible de la práctica legal debe paralelamente satisfacer dos requisitos: adecuación a esa práctica y mostración de su punto o valor. Pero aquí, punto o valor, no puede significar valor artístico porque el derecho, a diferencia de la literatura, no es una empresa artística.

h) El derecho es una empresa política que radica en la coordinación de los esfuerzos sociales e individuales, o en la resolución de los conflictos sociales o individuales, o en asegurar la justicia entre los ciudadanos, o entre ellos y el gobierno. A partir del argumento paralelo en literatura, sabemos que esta descripción de la interpretación en el derecho no es una autorización para cada juez de encontrar en la historia doctrinaria lo que él piense (voluntariosamente) que debería estar ahí. La misma distinción se mantiene entre interpretación e ideal. La obligación de un juez es interpretar la historia legal que encuentre, no inventar una mejor historia. La dimensión del acuerdo fijará ciertos límites. Desde luego no hay ningún algoritmo para decidir si una interpretación se adecua suficientemente. Pero la elección sobre cuál, entre diferentes y cruciales sentidos de la intención del legislador o del hablante, es el apropiado, debe ser decidida por cualquiera a quien le toque decidir como una cuestión de teoría política.

i) De algún modo derecho, arte y política, están unidos en la filosofía.

Investiguemos, en este momento del desarrollo de nuestro trabajo, en qué forma el otro jurista que hemos puesto en el equipo de los que se permiten un discurso sobre el vínculo del derecho y literatura, el Juez Posner de la Cámara de Apelaciones de los Estados Unidos y profesor de la Facultad de Derecho de Chicago, teoriza sobre el mismo fenómeno.

\section{Richard A. Posner o sobre cómo no conviene provocar a un economicista}

Richard A. Posner es un intelectual muy difícil de clasificar. Quien lo dude que le pregunte a Martha Nussbaum, una de sus críticas, que ha de haber tenido mi propia sensación luego de la lectura de sus textos. Por un lado, es el jurista más acreditado de la escuela económica del derecho (law and economics). Por el otro, redactor de uno de los libros más pulidos e iluminados sobre literatura y el derecho. Es decir, una especie de portador de la doble personalidad de Dr. Jekill y Mr. Hyde, del relato de Robert Louis Stevenson. En su condición de autor de derecho y economía suscita rechazos, que compensa muy largamente con sus trabajos sobre lo que llama «una relación incomprendida», la del derecho y la literatura.

En ocasiones, Harry Jekill se horrorizaba de los actos de Edward Hyde, pero se tranquilizaba de inmediato, liberando su conciencia. Después de to- 
do el culpable era Hyde, Hyde y sólo Hyde. El Dr. Jekill seguía siendo el mismo, volvía a sus buenas cualidades, para retornar de nuevo, por cierto, a las andadas. Por ejemplo, cuando con clon utilitarista reiteraba sus supuestos de que las personas son maximizadoras racionales de sus satisfacciones, a partir de las cuales se deducen sus conductas a captar por el derecho.

La novela Tiempos dificiles de Charles Dickens le sirve de símil a Nussbaum para comparar, sin proponérselo específicamente, al hombre de la doble personalidad con uno de sus personajes, Thomas Gradgrin.

En esta novela se desarrolla, irónicamente, una visión normativa de la vida no concebida sino como economía política científica, como imaginación política científica, a la manera en que lo hacía Jeremy Bentham ${ }^{25}$ con su «felicific calculus». Pero mientras hasta un utilitarista clásico, como Bentham y Sidgwick, admite que la riqueza no es sinónima de felicidad, esta idea no pasa por la mente de la escuela económica del derecho. El infranqueable abismo que hay entre las desdichas de los unos y la satisfacción de los otros, algo de lo cual el derecho no puede desentenderse, no ingresa tampoco en sus cálculos irremediablemente cuantitativos.

Un pasaje de la novela impresiona sobre el modo en que Thomas Gradgrin hace valer su teoría en el seno de la familia, con sus propios hijos. Cuando Louisa, atormentada por su inminente boda con Bounderby, exclama «Padre, a menudo he pensado que la vida es muy breve», su desconcertado padre responde:

«-Sin duda es breve, querida mía. No obstante está demostrado que la duración media de la vida humana ha aumentado en los últimos años. Los cálculos de diversas oficinas de seguros, entre otras cifras que no pueden estar erradas, han confirmado este dato.

-Hablo de mi propia vida, padre.

-¿De veras? Aún así, huelga aclararte, Louisa, que tu vida está regida por las leyes que rigen las vidas de la suma total».

Ignorando el misterio y la complejidad de cada vida, el señor Gradgrin está dispuesto a medir cada porción de la naturaleza humana y decir exactamente a qué se reduce. La simple aritmética -digamos, a la manera de la lógica deóntica en el derecho- cree ciegamente que mediante procedimientos sumatorios o tabulados puede resolver todos los problemas. ${ }^{26}$

Posner-economicista, lo adelantamos antes, pertenece al grupo de los fundacionalistas -cuyas características no los diferencian en sumo grado

${ }^{25}$ A Jeremy Bentham también le corresponde esa doble personalidad, en él marcada por su doble condición de economista y filántropo. Una condición cada día más distanciada en el capitalismo tardío globalizado.

${ }^{26}$ Martha Nussbaum: Justicia Poética, pg. 49. 
con los «fundamentalistas» teóricos-, es decir, de aquellos que se sienten seguros al ampararse en datos, contra los que estiman participan de ociosas fantasías. Posner-literario, al grupo de los antifundacionalistas, o como lo define él, al grupo de los no intencionalistas en literatura (permaneciendo como intencionalista en el derecho, y más por supuesto en el derecho económico). De acuerdo con esta bi-valencia, lo que hace el primero, el Mr. Hyde del law-economics, es usar esos datos no como necesarios para un pensamiento realmente racional, sino para implementar con ellos una operación dogmática, del tipo Gradgrin, incorporando el intelecto en una estructura que, al tiempo que prescinde de toda subjetividad, la subjetividad propia de los seres humanos, evapora de consuno lo social, y el contexto que modela aquella subjetividad, haciendo al hombre débil y a las distintas disciplinas que se ocupan de él incompletas, parcialmente mutiladas.

Los economistas, mejor aún «los economicistas», establecen, en efecto, una profunda brecha entre la razón y las emociones, dejando totalmente de lado la influencia que las emociones tienen en la propia construcción de las teorías, no menos que en las creencias y los juicios, como, a la recíproca, la influencia que las creencias y los juicios ejercen, a su vez, sobre las emociones. John Elster, Amartya Sen y la misma Nussbaum han estudiado muy bien estos aspectos y las consecuencias negativas de esta poda simplificada en los estudios. ${ }^{27}$

El análisis de esta última merecería un desarrollo más extendido del que se le puede dar, por lo cual me limitaré a enumerar algunos extractos: «la tradición del derecho no trata las emociones como fuerzas ciegas, que puedan anular la volición por su mera fuerza, sino como elementos del carácter de una persona. Se entiende que la gente es responsable de modificar sus emociones para integrarlas al carácter de una persona razonable... Las emociones son necesarias frente a la vulnerabilidad de la vida humana y de la necesidad de "bienes externos"... Si no existe la emoción, la creencia tampoco existe del todo... Así, los jueces o jurados que se niegan a sí mismos la influencia de la emoción, se niegan maneras de ver el mundo que parecen esenciales para aprehenderlo en plenitud. No puede ser (normativamente) racional pensar de esta manera aunque estemos haciendo economía... Los vínculos íntimos de amor y gratitud entre un hijo y sus padres, formados en la temprana infancia y alimentados en la niñez, parecen ser puntos de partida indispensables para desarrollar en el adulto la capacidad de hacer el bien en el mundo social. La represión de la emoción infantil, en

${ }^{27}$ Martha C. Nussbaum es una de las más competentes estudiosas del pensamiento griego. Puede verse en esta esfera La Fragilidad del Bien. Fortuna ética en la tragedia y la filosofía griega, Editorial Visor, Madrid, 1995. 
cambio, puede lograr que las emociones retornen de manera más destructiva, genuinamente irracional... Si somos socialistas serios -dice Williams- a menudo encontraremos en el interior de esta sustancia real -siempre tan sorprendente y vívida en los detalles (alude a la narrativa realista tradicional)- las profundas condiciones y los movimientos sociales e históricos que nos permiten hablar con voz plena, de una historia humana».

Adam Smith, el fundador de la economía moderna, no creía, por su lado, que la racionalidad ideal estuviera desprovista de emoción. Escribió, como sabemos, La Teoría de los sentimientos morales, y desarrolló una racionalidad emocional: «Las emociones apropiadas, es decir, las que son puramente racionales, son útiles para mostrarnos lo que podríamos hacer, y además poseen su propio valor moral, como reconocimiento del carácter de la situación que enfrentamos. Más todavía, motivan una acción adecuada... Si no partimos de la "Fantasía" para interesarnos en esas figuras humanas, sintiendo compasión por sus sufrimientos y alegría ante su bienestar; si no valoramos la importancia de encarar a cada persona como un individuo con una vida singular, nuestra crítica de las emociones perniciosas carecerá de fundamento ${ }^{28}{ }^{28}$

De Posner, ya vimos en su momento su opinión sobre El Mercader de Venecia, soldada a su opinión de economicista. Pero existe otra obra, en esta línea, también citada por Nussbaum, en que su extremo-Hyde llega a límites, por así decirlo, desopilantes, mas muy coherentes con su pensamiento. Se trata de Sexo y razón ${ }^{29}$, en la que transporta su economicismo al campo de la sexualidad: "Ahora examinemos los diferentes "tipos" de costo que supone la sexualidad, así como los principales factores que afectan estos costos. Uno es el costo de la búsqueda. Es cero para la masturbación en cuanto actividad solitaria, por lo que resulta la más barata de las prácticas sexuales (la acotación es importante: la "masturbación mutua", heterosexual u homosexual, es una forma de relación no vaginal pero sus costos de búsqueda son positivos)... Los hombres incurren en considerables costos de búsqueda por una call girl -y costos aún más elevados, por cierto, en el caso de una amante o de una esposa- pero en muy pocos por las "mujeres de la calle", prostitutas cuyo costo de búsqueda es cero y que sólo brindan servicios sexuales de calidad inferior. Análogamente, los bienes de calidad inferior se consumen en el hogar, no se despachan».

\section{${ }^{28}$ M. Nussbaum, pgs. 97 a 112.}

${ }^{29}$ Sex and Reason, Cambridge University Press, 1992. Ver en particular cap. 5, «Sex and Rationality», y las citas sobre el utilitarismo y la teoría económica, en las páginas 213-219 y 437-438. Asimismo de Posner y Catharine A. MacKinnon, Derecho y Pornografía, Universidad de los Andes, Colombia, 1996. 
Nussbam considera que se puede hablar seriamente de este modo, pero que ello no reduce sino que eleva el aporte crítico de una novela como Tiempos difíciles. Convengamos en que se trata de un modo si no desconcertante, que produce perplejidad, al menos «extraño» del hablar economicista y que, sin indagar a fondo, se encuentran ejemplos por doquier que lo validarían, si no tuvieran el inconveniente de centrar toda la vida en la economía. (Dicho en favor de Posner y entre paréntesis: en materia de amantes, por ej., la letra inefable y popular de algunos tangos traduce a la perfección la teoría. Basta que recordemos uno solo de ellos. La situación del hombre decepcionado que «mangó» (argentinismo) amigos, vio a usureros y estuvo un mes sin fumar, para comprar a su querida «aquel tapado de armiño todo forrado en lamé...», soportando luego su abandono. En materia de cónyuges, se ha hecho pública, en los medios, la cruz que para el futbolista Cannigia implican los lujos de Mariana Nannis, entre otros costos y costas, con sus valets y transporte-limousine. ¿Es posible dudar de «tiempos más difíciles» y gravosos para el amante y el esposo?).

Dejando las ironías y lo retintinoso (españolismo) de mis ejemplos, es evidente que no resulta factible reducir cada tramo de la existencia humana a transacción, cada ser humano a cifras en el pizarrón, o en la sección cálculos de una computadora de bolsillo.

Ahora bien; luego de formular al utilitarismo extremo y a Posner-economicista severas críticas, la catedrática de ética de la Universidad de Chicago dedica su libro a... Richard Posner. No es una contradicción. En la página de los Agradecimientos lo explica: La noche anterior a su primera conferencia Rosenthal tuvo la suerte de conocer a la persona que era el señor Grandgrin y su adversario intelectual. Se acercó a la mesa con aprehensión, dado lo común que es rebelarse contra la crítica. Sus temores pronto se disiparon. Encontró a una persona jovial y abierta, interesada por completo en el intercambio, supo que era un juez sumamente literario, como nuestro Tizón en la Argentina. Con el tiempo su colega, confiesa, contribuyó a hacer sus observaciones más sutiles. De gran capacidad para el diálogo y bonhomía. Se trataba de Posner-Hyde-Jekill.

Creo que cualquier lector, al menos es mi caso, de Law and Literature. A Misunderstood Relation, ha de tener la misma sensación. Dr. Jekill compensa y supera todos los extremos dañinos de Mr Hyde. Aunque es obvio que, para Posner mismo, esta metáfora de la doble personalidad stevensoniana le habrá de parecer por completo inadmisible (espero que no irrespetuosa). Si hay doble posición teórica, eso no apunta a una doble personalidad. No hay doble personalidad, pensará; hay una sola e idéntica personalidad, que no se disgrega en posiciones incompatibles, siendo ambas coherentes y valiosas. 
De cualquier modo, la dedicatoria del libro de Nussbaum a Posner, luego de sus fuertes críticas, revelaría que es mejor «no provocar a los economicistas», que es preferible dejar a los miembros de law and economic con sus tablas en el bolsillo, con sus fórmulas lógicas retozando dividendos. Esta misma moraleja debe haber tenido presente otra autora, Robin West, que usó la ficción de Franz Kafka como punto de apoyo para criticar sus posiciones (económicas), recibiendo por respuesta nada menos que el libro Law and Literature. Libro escrito con notable inteligencia por quien, como dice su prefacio, no había tomado -hasta ese momento- ningún interés en el movimiento derecho/literatura. ${ }^{30}$

Posner advierte el rápido crecimiento del campo de la investigación conocido como derecho-literatura, observando que sus representantes tratan de aplicar los métodos del análisis legal a los textos literarios y los métodos del análisis literario a los textos legales, detallando los cinco libros que se publicaron al respecto desde 1984. Se reconoce como firme partidario de los estudios interdisciplinarios, y habría suscrito con gusto el epígrafe de Carnap con que comenzamos este trabajo, admitiendo ser reconocido como constructor de puentes y no como intruso intelectual. Reconoce a su tarea como un intento de registro y evaluación general del campo, trata de organizarlo, aumentarlo y redirigirlo en el seno académico. Combina discusiones teóricas sobre puntos como la naturaleza y perduración de la literatura, modos en que la ley se refracta en el medio literario, el papel de las intenciones del autor en la interpretación de los textos legislativos y literarios, el vínculo entre el derecho y la justicia, y el lugar del estilo y los valores literarios que examina con una lectura y sutiles comentarios a las obras de Esquilo, Sófocles, Shakespeare, Marlowe, Dickens, Kleist, Dostoievski, Melville, Twain, Kafka, Camus, Yeats y otros. En sucesivos capítulos cubre cómo la literatura se aplica a los temas legales, y su influencia en la reflexión jurisprudencial, cómo el criticismo literario es y debe ser informado por el conocimiento legal, la aplicación de la teoría y la práctica literaria a los textos legislativos y judiciales, la regulación de la literatura por el derecho, y la defensa legal especialmente en las causas penales.

Desde luego Posner no abandona en absoluto su visión economicista. Considera que la relación inversa entre el precio de una mercadería y la cantidad demandada constituye un problema básico aplicable en el derecho, no

${ }^{30}$ El texto es de Robin West, y se llama «Authority, Autonomy and Choice: The Role of Consent in the Moral and Political Visions of Franz Kafka and Richard Posner». Fue publicado en 1985 en 99 Harvard Law Review 384. La respuesta-libro de Posner tiene la siguiente dedicatoria: «Para mi madre, quien me inició en los placeres de la literatura y mi padre, que me estimuló a seguir la Facultad de Derecho». Falta identificar al perverso «relative» que lo haya mezclado con el derecho económico. 
menos que aspectos vinculados a la regulación de accidentes a través de la ley de daños y perjuicios, la ley de monopolios y otros casos. En síntesis: el espíritu legal de la doctrina es económico, pero la relación entre el derecho y la literatura es menos ordenada y considerable, puesto que no hay una teoría literaria central que pueda ser tomada o aplicada al cuerpo del derecho.

De todos estos temas me concentraré en dos cuestiones que estimo los núcleos de su opinión. Primero, cuáles son las dificultades y cuáles las ventajas que Posner encuentra en el trazado de los puentes. En segundo lugar, la crítica que formula a Dworkin respecto de la «empresa en cadena».

\section{Dificultades:}

a) Los escritos legales están llenos de «ficciones legales», muchas veces bajo la forma de metáforas. Pero la semejanza con el uso literario de la metáfora es superficial. La ficción legal refleja el deseo de los jueces y los juristas de crear una apariencia de continuidad, cuando en realidad están innovando. $\mathrm{Si}$, como muchos juristas creen, ninguno es embaucado por una ficción legal, la herramienta es inofensiva, pero uno debe pensar entonces por qué se usan. La ficción, a despecho de su nombre, no es una herramienta literaria.

Es éste uno de los puntos más flojos del análisis de Posner. En efecto, lo que está considerando son ficciones que aparecen en los escritos de juristas y jueces, sin tomar en cuenta el papel que las ficciones cumplen en el derecho, las ficciones incorporadas a los textos constitucionales o legales, como el principio de la igualdad ante la ley, la autoridad de la cosa juzgada, etc., ficciones que se modelan en base a los estudios de la filosofía del «como si» de Hans Vaihinger, donde cumplen una función indispensable y enriquecedora, vista sobre todo desde la necesidad de adaptar la conducta de los hombres a los intereses del sistema económico-social vigente. Importantes juristas han estudiado las ficciones desde este ángulo, como Hans Kelsen, Summer Maine, Lon Fuller, Jerzy Wroblevsy, generando toda una doctrina a su respecto.

Además no es exacto que la ficción como herramienta literaria nada tenga que ver con las ficciones legales, ya que existen problemas comunes que Posner deja de lado: las cuestiones semánticas de referencia, el tipo de operación, en cada caso, para conectar, a través de uso, los textos con la realidad; el papel de las ficciones literarias en la teoría de la coherencia narrativa en el derecho, y otros. ${ }^{31}$

${ }^{31}$ Una abundante literatura se detecta en esta materia. Sobre la operatividad de las ficciones, en el sentido de Vaihinger, se realizaron muchas conferencias. Entre ellas, Die Zweite «Als Ob»-Konferenz in Halle ant 7 juni 1922; Charles Crittenden, «Thinking about non-Being», In- 
b) El énfasis de los juristas en emplear analogías, en comparación con la literatura, merece la misma observación que el caso de las ficciones. El poeta, afirma, al usarlas trata de sacudir al lector. El jurista, de sosegarlo. Por cierto, admite, las dos técnicas están firmemente relacionadas. Aquí Posner no agrega nada al trato de analogías, metáforas y ficciones que impliquen una crítica distinta de la esbozada anteriormente.

c) A veces el juez o el jurista usan un lenguaje figurativo, cuando expresan, por ejemplo, que «tasar es el sistema nervioso central de la economía». En la literatura se está bien preparados para no tomar literalmente lo que el escritor dice. Pero no ocurre lo mismo en un lenguaje discursivo analítico, propio del derecho. Millner Ball, en «Lying down Together; Law, Metaphor and Theology», analizando las opiniones que ven a la metáfora como un inescapable método por el cual atribuimos estructura a nuestra experiencia, arguyó sobre la conveniencia de sustituir las metáforas del derecho como un baluarte de libertad, por otra: la metáfora de que el derecho es un medio de solidaridad humana. Este punto entra en el mismo set que los dos anteriores.

d) Las ficciones legales en las decisiones judiciales, algunos de cuyos casos, sobre todo el relativo a la privacidad, es comentado. Me remito a la objeción formulada al punto a). Aun cuando aquí Posner amplía su marco anterior, de hecho le da poco desarrollo.

\section{Conexiones importantes admitidas por Posner.}

a) Aunque frecuentemente en materia literaria la importancia del derecho es empequeñecida, frente al amor, las situaciones de la vida, el asesinato, la religión, la guerra, la familia, el ascenso o más bien la escala social, el arte y la literatura misma, un sorprendente número de obras literarias se ocupan de procedimientos legales, donde algún tribunal de cierto tipo promueve un climax y ocupa un rol destacado. Como más arriba preanunciamos, el más destacado cuerpo de literatura gira acerca de «cuestiones» de justicia. Los ejemplos de venganza, a los que ya aludimos, se instalan en la transición del derecho, especialmente concebido a partir de la modernidad.

b) El derecho proporciona no sólo en la más conocida novela de Kafka, sino en sus historias y fragmentos, aspectos relevantes sobre la actividad tri-

quiry 16, p. 290-312; Avian Soifer, «Reviewing Legal Fictions», Georgia Law Review, n. 20, 1985; Kendall L. Walton, «Fearing Fictions», Journal of Philosophy, 1978. v. LXXXV; Colin Falck, «Fictions and Reality», Philosophy. v. 63 n. 245. 1988; Henry Summer Maine, «Legal Fictions», Harry Holt and Co., New York, 1877; Bernard Jackson, «Law, Facts and Narrative Coherence», Deborah Carles Pub, 1988; Tourtoulon, The Rational in Law; John Walter Jones, «Historical Introduction to the Theory of Law», Clarendon Pres, 1956; Frederic Williams Maitland, The Collected Papers of F. W Maitland, Cambridge University Press, 1911. 
bunalicia en general. King Lear contiene un tribunal irónico, lo mismo que Alicia en el país de las maravillas, que los críticos deberían intentar profundizar. No sólo Francis Bacon, sino Flaubert, Ariosto, Kafka, Wallace Steven y otros fueron juristas y, posiblemente, Chaucer.

c) Tanto la enseñanza legal como la literaria está directamente vinculada con el significado de los textos. En el caso del derecho hay constituciones, leyes, disposiciones administrativas, y fallos judiciales. La interpretación, es por ello, una cuestión central en ambos campos.

d) Muchos textos legales, especialmente fallos judiciales, se asemejan a los literarios en su retórica, más que a una fría exposición.

e) La literatura es, tradicionalmente, materia de regulación legal y, ocasionalmente, objeto de litigios. Muchos de ellos, aluden a derechos de autor, a difamación, a obscenidad y semejantes.

Hasta época muy reciente, la década del sesenta, a pesar de que los lazos entre ambas disciplinas eran numerosos, no fueron explorados, ni observados. La razón se debe a la sociología (yo agregaría asimismo, la psicología) del derecho universitario y de la literatura universitaria. Temas generales como la justicia y la interpretación, que deberían haber sido comprendidos en gran parte desde el estudio de los textos literarios y los métodos literarios, recibieron muy poca atención. El vacío fue ocupado por no académicos y por audiencias cultivadas en ambos campos. Por ejemplo, jueces como Cardozo, Holmes y, entre nosotros, Héctor Tizón, se volcaron al pensamiento legal tomando en cuenta la literatura.

Esta caracterización ha sido influida, como antes lo expusiera Dworkin, por un incremento de la politización en ambas disciplinas, lo que señala una nueva convergencia: la política. Los profesores de derecho y de literatura ofrecen la posibilidad de una esperanza en «la redención» de un futuro tecnocrático (palabras de Posner) y los de la literatura de la marginalidad social, distinción esta que de todos modos está poco clara. En efecto, al otorgar Posner la posibilidad de lucha contra la marginalidad exclusivamente a la literatura, privando de ella al derecho, priva a éste de una de sus funciones, sin argumento consistente alguno.

Ahora bien, dado el inventario de ambas listas (dificultades y ventajas), no inhibe a Posner de advertir que, a pesar de haber aparecido en el nivel universitario, y en ambos campos, mayor predisposición a tender el puente, éste ha logrado hasta el momento escasos éxitos. Algunos practicantes han exagerado las notas comunes prestando insuficiente atención a las diferencias profundas.

En este sentido, no puede dudarse que, en última instancia, frente a su inventario de los pro y los contra, su posición es ambigua, o usando las palabras de él emanadas, ecléctica en sumo grado, pero el campo está en con- 
diciones de estimular nuevas investigaciones, una nueva comprensión de lo que se debate, y esto se puede obtener tanto acentuando las diferencias como las similitudes, o hablando con más propiedad, detectando las conexiones. El training y la experiencia práctica de los juristas no los equipa para leer literatura, percibiendo en ella lo que es aplicable al derecho. El caso de Dworkin es una notable excepción.

Los juristas son muy conservadores. Están muy apegados al derecho estricto por razones de defensa profesional, y sujetos a la influencia del positivismo y el formalismo de la teoría pura del derecho. Esto ha incidido en contra de todo proyecto de interdisciplinariedad tanto con la sociología como con la moral, la psicología y con la teoría del poder, vía los análisis del «Otro Kelsen», cuyos textos han sido manifiestamente excluidos de la enseñanza de casi todas las Facultades de Derecho del mundo.

Posner estima que el cuerpo de literatura dirigido más directamente al derecho, como Antígona, Bleak House, Billy Budd y The Trial, tanto como los trabajos de Shakespeare, quizá tengan poco que ver con la tarea relevante de un jurista profesional. Pero esto se debe, ante todo, a la estrechez de miras de ese profesional sobre la idea del derecho. El jurista que lee tales obras puede disfrutar, con ellas, de fructíferas reflexiones acerca de la tensión que existe entre los conceptos formales legales y las nociones éticas más amplias de justicia. Incluso la comprensión de las diferencias entre la interpretación legal y la literaria se encuentra en condiciones de mejorar nuestro entendimiento del derecho en forma indirecta.

La posibilidad misma de enseñar abogacía a partir de los grandes ejemplos literarios de elocuencia y persuasión, como las oraciones funerarias de Julio César, se han pasado por alto. Lo mismo ha ocurrido con los avatares del tribunal de Dimitri Karamazov. La actuación del abogado de Dimitri, Fetyukovitch, demuestra dos aspectos fundamentales de la práctica efectiva de un tribunal: preparación meticulosa y una teoría del caso que el abogado crea organizando, seleccionando y refundiendo los hechos en bruto, para hacer inteligible, coherente y atrayente la historia.

Por supuesto, Posner previene, que en toda actividad interdisciplinaria el peligro mayor es el amateurismo, a lo que agrega otra prevención muy importante: el abogado que escribe acerca de literatura puede seducir o deslumbrar a otros abogados, de la misma manera que el literato que escribe sobre derecho puede deslumbrar a otros hombres de letras y, en ningún caso, los deslumbrados están en condiciones de evaluar la calidad de la contribución.

Pero lo que se propone Posner, básicamente, es promover la causa de los estudios interdisciplinarios, estimular la recíproca incorporación de los es- 
tudios de derecho y literatura en las Facultades alternas, no menos que un fresco pensamiento en el eterno problema de la ley y la justicia.

He reservado la última instancia de este trabajo para examinar la crítica que Posner formula a «la empresa en cadena» de Dworkin, es decir su opinión en materia de interpretación, en la que, como surgiera del estudio de Gadamer y de otros autores, está instalado el núcleo decisivo del puente literatura-derecho.

En términos generales, Posner observa que aunque Dworkin no se incluya en la corriente antifundacionalista llamada «New Criticism», e incluso sus discusiones sobre teoría literaria sean más bien breves y vagas, se le puede asignar muy bien dicha pertenencia por varias razones. En primer lugar, un «nuevo crítico» trata una obra de literatura como un artefacto, coherente en sí mismo, y sin ocuparse de los detalles de la biografía del autor o de otras circunstancias de su composición. Con relación a un texto legal, lo importante para un «nuevo crítico» (son sus más importantes representantes A. C. Bradley, Cleanth Brooks, W. K. Wimsatt) es asignar un significado coherente y satisfactorio.

Los «intencionalistas», por su parte, se definen con otra matriz: la creencia de que la vía para comprender una obra de literatura es reconstruir las intenciones del autor, el significado que le asigna a la obra, o que le hubiese asignado de haber reflexionado sobre ella.

Dworkin rechaza claramente el intencionalismo y no trata el extremo escepticismo de la escuela de la respuesta-del-lector, cuya forma germánica, según lo expusiéramos, recibe el nombre de Estética de la Recepción (Wolfgang Iser, Odo Marquard, Hans Robert Jauss). Y quizá, arriesga Posner, lo que Dworkin piense es que toda interpretación es contextual y los principios políticos forman parte del contexto interpretativo de las constituciones y las leyes.

Conforme a Posner -quien asume la posición de un «intencionalista» en derecho y un «nuevo crítico» en literatura-, Dworkin usa o usaría en la interpretación legal estándares no literarios sino filosóficos. Leería toda disposición en una vía que pudiera hacer de ella «el mejor enunciado de filosofía política»; pero el problema radica, justamente, en que no hay acuerdo en la filosofía política sobre cuestiones esenciales. Hay filósofos libertarios como Nozick (con el uso muy particular con que los norteamericanos emplean la palabra «libertario», asociando a Nozick en el extremo del absurdo con Kropotkin, Bakunin, Ricardo Mella o Buenaventura Durruti), los hay igualitarios como el mismo Dworkin y Rawls, y muchos matices entre ellos, circunstancia que hace muy ambigua la posición de quien Posner critica.

En cuanto al más destacado de los intencionalistas en literatura, Hirsch, ya vimos antes sus puntos de vista. Hirsch refuta, en defensa del autor, los 
siguientes ataques de los antifundacionalistas, tendentes a justificar su destierro. A saber:

1. «El significado de un texto cambia, incluso para el autor»

No hay duda de que la «significance», la significación de una obra, ha cambiado para un autor, pero no el «meaning», significado o sentido. El «meaning» es lo que está representado por el texto, lo que el autor significa por su uso de una particular secuencia de signos. Consiste en lo que el signo representa. Por el otro lado, «significance» nombra una relación entre el significado y una persona o una concepción, o una situación o, incluso, algo imaginable.

Los autores pueden cambiar con el tiempo sus actitudes u opiniones, incluso sus criterios de valor y ver su propia obra en diferentes contextos. Pero lo que cambia, obviamente, es su relación con el significado, no el significado mismo. De ahí que cuando los críticos hablan de cambios de significado, de lo que están hablando, en realidad, es de cambios en la significación.

2. «No importa lo que el autor dice, sólo importa lo que dice el texto»

Se trata de un dogma en la doctrina de la autonomía semántica, fundamental para el problema de la validez. Si fuese verdadero, entonces cualquier lectura sería válida, toda vez que cualquier lectura se correspondería con lo que el texto dice para el lector.

3. «El significado del autor es inaccesible»

Este punto de vista es propio tanto del historicismo radical, como de una teoría que sostiene que los textos son ontológicamente distintos de otros textos no-literarios. Se trata de algo, según Hirsch, altamente improbable. La afirmación no puede ser sometida, como se lo hace, a una generalización empírica, pues ni la teoría ni la experiencia la pueden confirmar o negar decisivamente. La interpretación de los textos está vinculada exclusivamente con significados compartidos, y no todo lo que estoy pensando cuando escribo puede ser compartido por otros. Hay textos que por su antigüedad conservan un significado ahora inaccesible, pero semejante escepticismo, en forma generalizada, está muy lejos de ser aceptable.

4. «A menudo el autor no sabe lo que significa»

Ocurre a menudo que un autor no conoce lo que piensa, o lo que dice en sus textos. Ya Platón lo expresaba en la Apología 22 b-c. Kant afirmaba que, incluso Platón, no conocía lo que pensaba (Crítica de la Razón Pura A 314 
B B 370), y que él podía entender algunos de los escritos de Platón mejor que Platón mismo. Hay muchas variantes de ignorancia autorial. Pero que un hombre no sea consciente de todo lo que piensa no es más notable de que no sea consciente de todo lo que hace. Ningún ejemplo de ignorancia autorial, respecto a su significado, puede mostrar que la intención de su significado y el significado de su texto son diferentes.

Dworkin no acepta el intencionalismo. Éste asigna primacía en la creación del significado de una obra de literatura al autor (en el plano legal, sería al legislador); la Estética de la Recepción lo atribuye a la respuesta del lector, el crítico o algún otro (en el derecho al juez o al jurista doctrinario) y la Nueva Crítica a la obra en sí misma. Es esta última, como vimos, la posición que Posner asigna a Dworkin, en la medida en que el autor de Law's Empire's juzga que la interpretación no debería ser puesta en el pequeño espacio de la mente autorial ni, en el otro extremo, constituye un medio plástico en el que cada lector expresa su propia creatividad. Para Dworkin lo importante es la obra y su contexto socio-político.

Es bueno tener presente que Posner, al desacreditar el intencionalismo en materia literaria (aceptándolo sólo en el derecho) no intenta denegar que una obra literaria es una creación humana deliberada, pero de aquí no se sigue que la interpretación literaria sea fructífera si la colocamos del lado de las intenciones del autor. Ahora bien, al manifestar ese dualismo entre textos literarios (nuevo crítico) y textos legales (intencionalista) lo que está haciendo, en el fondo, es objetar la lectura de ambos tipos de textos en la misma forma; algo que resulta impropio, convengamos, en opinión de Dworkin, para quien derecho y literatura marcan los mismos pasos en interpretación, se ponen en la misma fila.

Sin embargo, Dworkin, observa Posner, desarrolla una nueva posición con su propuesta de la «empresa en cadena», cuya metodología y pasos examinamos antes. La analogía de Dworkin, sostiene críticamente Posner, iguala los intérpretes de la Constitución con los autores de la misma; punto de vista, por lo demás, muy moderno. Pero incluso la descripción de la «empresa en cadena» es engañosa. ¿Por qué? ¿En qué sentido?

Lo que va a sostener su crítica, en ultima instancia, es que la cadena, como diría Lenin, «se rompe por el eslabón más débil». Ante todo, el capítulo 1, en la evolución de la doctrina del derecho común, es altamente tentativo, opera como un prefacio o introducción. En segundo lugar, los autores de los capítulos subsiguientes no están obligados a adherirse a la dirección que les señala el autor del primero. Si la experiencia demuestra que el capítulo 1 tomó una dirección equivocada, los jueces pueden descartarlo. Un tercer punto es que las doctrinas del derecho común tienden a evolucionar en un largo período de tiempo, durante el cual las condiciones antecedentes 
están cambiando y los cambios habrán de influir en los últimos capítulos, incluso si el resultado es hacerlos discordantes con los primeros. En síntesis: «The final oddity about Dworkin's analogy is that there are no good chain novels». En buen romance, podría no existir ningún derecho constitucional bueno, si se construyera sobre la base de la analogía de la novela en cadena.

Esta misma dirección de la impugnación la toma el crítico literario Stanley Fish en "Working on the Chain Gang. Interpretation in Law and Literature», de su citado libro. Admitiendo que la posición de Dworkin es útil e iluminadora, señala algunos aspectos de desacuerdo. Asume el ejemplo dworkiniano de que el primer miembro de la cadena está en una posición diferente con respecto de aquellos que lo siguen porque él es el único creador, mientras que los otros deben tanto crear como interpretar. La idea de una primera versión, cambiada luego por Dworkin, es que el primer autor no está obligado a leer todo lo que ha pasado antes, pudiendo decidir cómo son los personajes, qué motivos los guían, etc. Pero de hecho, el primer autor también ha comprometido su libertad tan pronto como se comprometió a escribir una novela, decisión que hace bajo las mismas constricciones que sus colaboradores. Debe decidir, por ejemplo, cómo empezarla, en lo que ya no es libre, porque «escribir una novela» existe en el contexto de un conjunto de prácticas que al mismo tiempo que lo habilitan, limitan el acto del comienzo. Esto no quiere decir que se encuentre totalmente determinado, sino que sus elecciones disponibles son «novel writing choices». Como se percibe nuestro jurista Posner, y nuestro crítico literario Fish, componen un mismo tipo de crítica al pensamiento de Dworkin, ajeno, en cambio, a la dirección de Neil MacCormick y A. Aarnio.

\section{Conclusiones}

Como hemos visto a lo largo de este escrito, el enlace, el puente entre derecho y literatura, ha recibido distintas respuestas en ambos campos.

- Para Carnap, es algo totalmente vedado. Con Wittgenstein diría: «De lo que no se puede hablar, mejor es callar». Su régimen fonológico: el silencio o el rechazo absoluto. En todo caso, un puente sobre el río Kwai. Carnap se enamora del puente, como Alec Guinness, pero su pasión no llega a tanto como querer preservarlo en su totalidad.

- Para Gadamer, inspirador privilegiado del antifundacionalismo, se puede hablar en voz alta. Más aún, hay que hacerlo con megáfono.

- Para los antifundacionalistas, como Fish, y los miembros de la Estética de la Recepción, muy probablemente se pueda hablar.

- Para los fundacionalistas, muy probablemente no se pueda hablar (Hirsch). 
- Para Dworkin, se puede hablar con voz alta. La estructura del puente es sólida. Con tal convicción, se puso estructurar una teoría, sin notar que la fuerza de su Hércules podía trastabillar.

- Para Posner se puede hablar, pero en voz baja, quizá para no molestar a Mr. Hyde. Más que de puente, se inclinaría por una pasarela, a convertir en puente en una situación más desarrollada de la doctrina.

- A la academia del derecho, le va a costar mucho salir del estado de ciego, «sordo y mudo». Mejor que un puente, prefiere un subterráneo que la conduzca, firme y segura, por una sola vía. Cuestión de defensa profesional. El puente, como a Monsieur Dupin y los positivistas -que, en rigor, forman la Academia en la teoría del derecho- se les presenta como «extraño».

- A los hombres de letras y los críticos literarios, pese a su desconfianza sobre los «hombres de negro y cuellos de oca», no les costará tanto. 
